\title{
Mesoporous silica nanoparticles as a compound delivery system in zebrafish embryos
}

This article was published in the following Dove Press journal:

International Journal of Nanomedicine

10 April 2012

Number of times this article has been viewed

\section{Faiza Sharif ${ }^{\prime, *}$ \\ Fabiola Porta ${ }^{2, *}$ \\ Annemarie H Meijer ${ }^{3}$ \\ Alexander Kros ${ }^{2}$ \\ Michael K Richardson' \\ 'Department of Integrative Zoology, Institute of Biology, ${ }^{2}$ Leiden Institute of Chemistry, ${ }^{3}$ Department of Molecular Cell Biology, Institute of Biology, Gorlaeus Laboratories, Leiden University, Leiden, The Netherlands \\ *These authors contributed equally to this work}

Correspondence: Michael K Richardson Department of Integrative Zoology, Institute of Biology, Leiden University, Sylviusweg 72, 2333BE, Leiden,

The Netherlands

Email m.k.richardson@biology.leidenuniv.nl
Abstract: Silica nanoparticles can be efficiently employed as carriers for therapeutic drugs in vitro. Here, we use zebrafish embryos as a model organism to see whether mesoporous silica nanoparticles (MSNPs) can be incorporated to deliver compounds in vivo. We injected $35-40 \mathrm{~nL}(10 \mathrm{mg} / \mathrm{mL})$ of custom-synthesized, fluorescently-tagged $200 \mathrm{~nm}$ MSNPs into the left flank, behind the yolk sac extension, of 2-day-old zebrafish embryos. We tracked the distribution and translocation of the MSNPs using confocal laser scanning microscopy. Some of the particles remained localized at the injection site, whereas others entered the bloodstream and were carried around the body. Embryo development and survival were not significantly affected by MSNP injection. Acridine orange staining revealed that MSNP injections did not induce significant cell death. We also studied cellular immune responses by means of $l_{y s} C:: D s R E D 2$ transgenic embryos. MSNP-injected embryos showed infiltration of the injection site with neutrophils, similar to controls injected with buffer only. In the same embryos, counterstaining with L-plastin antibody for leukocytes revealed the same amount of cellular infiltration of the injection site in embryos injected with MSNPs or with buffer only. Next, we used MSNPs to deliver two recombinant cytokines (macrophage colony-stimulating factor and receptor for necrosis factor ligand) to zebrafish embryos. These proteins are known to activate cells involved in bone remodeling, and this can be detected with the marker tartrate-resistant acid phosphatase. Coinjection of these proteins loaded onto MSNPs produced a significant increase in the number of tartrate-resistant acid phosphatase-positive cells after 2-3 days of injection. Our results show that MSNPs can be used to deliver bioactive compounds into zebrafish larvae without producing higher mortality or gross evidence of teratogenicity.

Keywords: mesoporous silica nanoparticles, toxicity, immune cells, TRAcP, L-plastin, lysozyme

\section{Background}

Recent years have witnessed an impressive growth of fundamental and applied research in the field of nanoscience and nanotechnology. ${ }^{1}$ There is a wide variety of nanomaterials, including metal nanoparticles, nanoshells, fullerenes, quantum dots, polymer nanoparticles, dendrimers, and liposomes. ${ }^{2-8}$ In the future, these nanomaterials may be applied in disease diagnostics and for drug delivery targeted at specific sites (eg, in the treatment of cancer). ${ }^{9}$

The burgeoning field of nanomaterials brings several advantages to the design of new drug delivery systems (DDS), as they possess significant properties, such as a high surface area and a tunable pore size, shape, and diameter, resulting in high loading capacity of drugs. In addition, the outer surface can be easily modified to achieve targeted release. ${ }^{10}$ 
The design of an efficient DDS is crucial for use in medical applications; therefore, it has to present a number of properties, such as manipulation of biological profiles (eg, pharmacokinetics and pharmacodynamics, biodistribution, and cellular uptake). ${ }^{11}$ There are two important challenges in these fields: (1) the DDS must protect their cargo from enzymatic degradation and induce a minimal immune response, and (2) it has to ensure delivery to the desired site followed by release of the active drug. To meet these challenges, the DDS has to present some prerequisites, such as biocompatibility with the biological environment, efficient cellular uptake, and controllable rate of release, to achieve an effective local concentration. ${ }^{12,13}$ Mesoporous silica nanoparticles (MSNPs) have the potential to satisfy all of these requirements. ${ }^{11}$

Previous studies have shown that nonphagocytic eukaryotic cells can endocytose latex beads up to $500 \mathrm{~nm}$ in size, and that the efficiency of uptake decreases with increasing particle size.${ }^{14}$ Particles around $200 \mathrm{~nm}$ in size or smaller are taken up with highest efficiency, whereas very little uptake is observed for the particles larger than $1 \mu \mathrm{m}$. Therefore, MSNPs can be efficiently employed as carriers for intracellular drug delivery. ${ }^{14}$ It was found in other studies that the toxicity of nanoparticles may vary with size, structure, and composition. ${ }^{15,16}$ Acute toxicity occurs at nanoparticle concentrations in the order of milligrams per liter in the case of the medaka, Oryzias latipes, and the largemouth bass, Micropterus salmoides. ${ }^{17,18}$ Silica nanoparticles were found to be nontoxic to other human and mouse embryonic cells at up to $15 \mathrm{mg} / \mathrm{L} .{ }^{19}$ In addition, silica nanoparticles have not been found to have general or overt toxicity between $0.0025 \mathrm{mg} / \mathrm{L}$ and $200 \mathrm{mg} / \mathrm{L}^{20}$

Mice have been used for studying nanoparticle biology. ${ }^{21}$ Organs that can take up nanostructures in mice include the spleen, lymph nodes, and bone marrow. All of these are major organs of the immune system and contain large concentrations of phagocytic cells that can ingest the nanostructures. Nanostructures that are coated with the polymer polyethylene glycol (PEG) have shown to be more resistant to uptake by phagocytic cells. ${ }^{22}$

Zebrafish transgenic lines that express green or red fluorescent proteins (DsRED2) under a neutrophil-specific promoter, such as the myeloperoxidase ( $m p x)$ promoter ${ }^{23,24}$ or the lysozyme $\mathrm{C}(l y z)$ promoter, ${ }^{25}$ provide useful in vivo models for real-time imaging and genetic analyses of inflammatory responses. Neutrophils and macrophages in zebrafish larvae can be visualized by immunolabeling with anti-L-plastin antibody, whereas the expression of csflr (colony-stimulating factor-1 receptor) and the lack of $m p x$ and $l y z$ expression in macrophages can be used to distinguish them from neutrophils. ${ }^{23,26}$ The elongated morphology of the cells expressing these markers further points to a macrophage identity. ${ }^{23}$ Both the neutrophil and the macrophage populations are involved in the innate immune response toward infection and injury. ${ }^{23-26}$ In order to understand the fate and interaction of nanomaterials with the immune cells, further studies are needed.

Many features of the zebrafish (Danio rerio) model make it well suited for studies of nanomedical applications. It has a short generation time (around 3 months) and a large clutch size (200-300 eggs), which allows high-throughput assays at low cost. ${ }^{27}$ Zebrafish embryogenesis is rapid, with most of the internal organs, including the heart, liver, intestine, and kidney, developed by 96 hours post fertilization. ${ }^{28}$ The optical transparency of zebrafish embryos and their fertilization and development outside the mother enable an easy and thorough observation of drug effects on internal organs in vivo.

The zebrafish is also a very attractive model for studying the mechanisms underlying bone formation, ${ }^{29,30}$ because the key regulators of bone formation are highly conserved between mammals and teleosts, and the corresponding orthologs share significant sequence similarities and an overlap in expression patterns when compared with mammals. ${ }^{31-33}$ Molecules essential to promoting osteoclastogenesis ${ }^{34}$ include (1) macrophage colony-stimulating factor (M-CSF), (2) receptor for activation of tumor necrosis factor kappa $\mathrm{B}$ (TNF-KB or receptor for necrosis factor [RANK]), and (3) RANK ligand (RANK-L, OPGL, or TRANCE).

The aims of this study are (1) to test the toxicity of MSNPs on zebrafish embryos, (2) to test the effect of MSNPs on immune cells, and (3) to see whether MSNPs can be used to deliver bioactive compounds into zebrafish larvae. For this latter objective we chose M-CSF and RANK-L because they have a clearly defined biological readout: the activation of osteoclasts. ${ }^{35}$

\section{Materials and methods Silica nanoparticle synthesis}

MSNPs were synthesized via sol-gel chemistry using hexadecyl trimethyl ammonium bromide (CTAB) and mesitylene as templates. ${ }^{11}$ In a flask, $1.0 \mathrm{~g}(2.7 \mathrm{mmol})$ of CTAB and $480 \mathrm{~mL}$ of Milli-Q water (Millipore BV, Amsterdam, The Netherlands) were mixed and stirred at $80^{\circ} \mathrm{C}$. Next, $3.5 \mathrm{~mL}$ of $\mathrm{NaOH}$ $2 \mathrm{~N}$ (aq) and $7.0 \mathrm{~mL}$ (48.8 mmol) of mesytilene were added. After 2 hours, $5 \mathrm{~mL}(21.9 \mathrm{mmol})$ of tetraethoxysilane was added and the suspension was stirred for another 2 hours. The 
suspension was filtered and a white powder was recovered (yield 60\%). The CTAB and mesitylene were removed from the silica nanoparticles by acid methanol extraction. A total of $1.5 \mathrm{~g}$ of MSNPs was suspended in $160 \mathrm{~mL}$ of methanol with $9 \mathrm{~mL}$ of $\mathrm{HCl} 12 \mathrm{~N}$, and the mixture was refluxed overnight under a nitrogen atmosphere. The MSNPs were recovered by filtration and dried overnight at room temperature under normal pressure. The removal of the template was confirmed using Fourier transform infrared spectroscopy (FT-IR).

\section{Surface modification of the silica nanoparticles}

A total of $100 \mathrm{mg}$ of MSNPs was suspended in $10 \mathrm{~mL}$ of toluene. After sonication, 2-(methoxy [polyethyleneoxy] propyl) trimethoxysilane $0.1 \mathrm{mmol}(0.431 \mathrm{~g}, 0.400 \mathrm{~mL})$ was added, and the reaction mixture was refluxed overnight. The product was recovered via filtration, resulting in a white powder with a yield of $76 \%$.

\section{Synthesis of fluorescent MSNPs for imaging}

The synthesis of fluorescent-labeled MSNPs was performed in accordance with a procedure by Lu et al. ${ }^{12}$ In brief, $5.5 \mathrm{mg}$ (0.014 mmol) of fluorescein-5(6) isothiocyanate (FITC) was dissolved in $3 \mathrm{~mL}$ of absolute ethanol and $12 \mu \mathrm{L}(0.051 \mathrm{mmol})$ of (3-aminopropyl) triethoxysilane (APTES). The mixture was stirred under nitrogen atmosphere for 2 hours. In a different flask, $0.5 \mathrm{~g}$ (13.5 mmol) of CTAB was dissolved in $240 \mathrm{~mL}$ of Milli-Q water with $1.75 \mathrm{~mL}$ of $\mathrm{NaOH} 2 \mathrm{~N}$. The solution was heated to $80^{\circ} \mathrm{C}$ and stirred vigorously. Once the temperature stabilized, $2.5 \mathrm{~mL}(11.12 \mathrm{mmol})$ of tetraethoxysilane was added together with the solution of the functionalized APTES previously synthesized. The mixture was stirred for another 2 hours at $80^{\circ} \mathrm{C}$, and the MSNPs were recovered by filtration and dried overnight at room temperature under normal pressure. The MSNPs recovered were in the form of a yellow fine powder, giving a final yield of $60 \%$. The CTAB template was removed from the silica nanoparticles by suspending $1.5 \mathrm{~g}$ of the particles in $160 \mathrm{~mL}$ of methanol with $9 \mathrm{~mL}$ of $\mathrm{HCl} 12 \mathrm{~N}$ and the mixture refluxed overnight under an inert atmosphere. The removal of the template was confirmed using FT-IR. The product was recovered via Büchner filtration, resulting in a yellow powder.

\section{Scanning electron microscopy and transmission electron microscopy}

MSNPs were suspended in methanol and sonicated in order to avoid aggregation. A total of $10 \mu \mathrm{L}$ of suspension was deposited on an aluminum stub and coated with pure carbon with a sputter carbon coater. Transmission electron microscopy was performed with a JEOL 1010 instrument (Tokyo, Japan) at $60 \mathrm{kV}$. The sample was prepared as stated previously and was deposited on a carbon-coated copper grid and then air dried for 3 hours.

\section{X-ray diffraction}

The X-ray diffraction spectrum of the MSNPs was measured with a powder diffractometer with $\mathrm{Cu}$ radiation at $40 \mathrm{kV}$ and $30 \mathrm{~mA}$.

\section{Loading of FITC-bovine serum albumin into MSNPs}

For the loading of FITC-bovine serum albumin (BSA) into the MSNPs, $5 \mathrm{~mL}$ of phosphate-buffered saline (PBS; $\mathrm{pH} 7.24$ ) containing $1 \mathrm{mg} / \mathrm{mL}$ of FITC-BSA was stirred for 24 hours at room temperature in the presence of $50 \mathrm{mg}$ of MSNPs. The suspension was then centrifuged and the loading determined by measuring the absorbance of the Soret band of the BSA $(280 \mathrm{~nm})$ in the supernatant before and after the loading. The loading capacity of the PEG-MSNPs was determined with ultraviolet-visible (UV-vis) spectroscopy, resulting in a loading of $0.5 \mathrm{mmol}$ of BSA per gram of PEG-MSNPs.

\section{Release of FITC-BSA from MSNPs}

Release of FITC-BSA from MSNPs was measured in $1 \mathrm{M}$ PBS at pH 7.24 by preparing a suspension of $1 \mathrm{mg} / \mathrm{mL}$ of loaded MSNPs. MSNPs were washed twice in PBS to remove excess FITC-BSA. The release was determined by taking aliquots at different times. The aliquots were centrifuged, and the UV-vis absorbance of the FITC-BSA was measured to give quantitative information about the release.

\section{Zebrafish embryos}

All experimental procedures were conducted in accordance with the Netherlands Experiments on Animals Act, which serves as the implementation of "Guidelines on the protection of experimental animals" by the Council of Europe (1986), Directive $86 / 609 / \mathrm{EC}$, and were performed only after a positive recommendation of the Animal Experiments Committee had been issued to the licensee. All procedures were carried out in accordance with humane care and treatment where required.

Maintenance of zebrafish (Danio rerio) adults took place at $26^{\circ} \mathrm{C}$ in aerated 5 liter tanks, in a 10:14 hour light: dark cycle. In each mating setup two females and one male fish were present. The eggs were collected within the first hour, cleaned, sorted, and transferred to Petri dishes filled with 
egg water (0.21 gm Instant Ocean ${ }^{\circledR}$ salt (Salt Mentor, OH) in 1 liter of demi water). Embryos were anesthetized with $0.04 \%$ MS-222 (tricaine methane sulfonate) at 2 days post fertilization (dpf) for microinjections.

\section{Mesoporous silica nanoparticle injections}

The embryos were divided into two groups: treatment (injected with MSNPs in PBS) and control (injected with PBS only). The embryos (2 dpf) were anesthetized and transferred to custom-made agarose gel moulds to hold them in place. The moulds were made with 5\% agarose in PBS (molecular grade, Bioline Cat. BIO-41025; Bioline GmbH, Luckenwalde, Germany), boiled to dissolve, and then cooled. Borosilicate glass capillaries with $1 \mathrm{~mm}$ outer diameter $\times 0.78 \mathrm{~mm}$ inner diameter (Cat. GC100TF-10, Harvard Apparatus, Holliston, MA) were pulled using a needle puller. The resulting flexible, thin, closed tip was snapped off to open the capillary for injecting. Each tip was calibrated for the release of fluid in oil, and the diameter of the droplet in oil recorded. About 35-40 nL of MSNP suspension was injected into the left flank of each embryo caudal to the yolk sac extension with an air pulse provided by a Parker Picospritzer 3 (Parker Hannifin, Pneutronics Division, NJ) at a pressure of $30 \mathrm{psi}$ and time $10 \mu \mathrm{sec}$. The pulse was delivered immediately after the needle had been pushed through the epidermis.

Human recombinant M-CSF (R\&D Systems, Inc, Minneapolis, MN; Catalog Number 216-MCC) $40 \mathrm{ng} / \mathrm{mL}$ and RANK-L (R\&D Systems, Inc; Catalog Number 390-TN) $400 \mathrm{ng} / \mathrm{mL}$ in combination were loaded into MSNPs by soaking overnight. The protein-loaded MSNPs were then centrifuged, and the supernatant was removed. The resulting MSNPs were resuspended in $1 \times$ PBS. This MSNP suspension in PBS was injected into 2-day-old embryos, and the embryos were fixated at 1 day, 2 days, 3 days, 4 days, and 5 days post injection for tartrate-resistant acid phosphatase (TRAcP) enzyme staining. We used pegylated and nonpegylated MSNPs to test the toxicity in zebrafish embryos (as mentioned in Toxicity testing). There was no difference in the toxicity between the pegylated and nonpegylated MSNPs; therefore, we used pegylated MSNPs for our studies, as pegylated beads were previously reported to be more resistant to phagocytosis. . $^{36,37}$ After injection, the embryos were washed twice with fresh egg water and transferred into Petri dishes (30 embryos per dish) and maintained at $28^{\circ} \mathrm{C}$ until analysis.

\section{Embryo imaging and analysis}

Imaging (including time-lapse recording) was done with confocal microscopy (Zeiss Observer LSM 500 inverted microscope; Carl Zeiss BV, Sliedrecht, The Netherlands), immediately after injection, and 24 hours post injection, to assess the uptake and distribution of the fluorescent MSNPs in the body of the living embryo. We recorded mortality, malformations, and cell death as described in Supplementary information, Analysis of zebrafish embryos.

\section{Transgenic lysC::DsRED2 embryos for neutrophils}

The transgenic lysC::DsRED2 embryos used in this study have been described previously. ${ }^{25}$ The neutrophil specificity of this line is supported by other studies. ${ }^{38}$ Two groups, each consisting of 35 eggs, were injected with or without MSNPs. Embryos were imaged within 2-5 hours post injection, at 24 hours, 2 days, and 3 days post injection with confocal microscopy.

\section{L-plastin immunostaining}

For L-plastin immunostaining, we used the procedure adapted from Cui et al. ${ }^{39}$ Incubation was done overnight at $4{ }^{\circ} \mathrm{C}$ with rabbit anti-L-plastin ${ }^{40}$ in blocking buffer (PBS-TX containing 1\% BSA, 1:500 dilution). Embryos were incubated for 2 hours at room temperature in Alexa Fluor 405 goat-antirabbit antibody (Invitrogen Corporation, Carlsbad, CA; 1:200). They were stored at $4^{\circ} \mathrm{C}$ and imaged using confocal microscopy (Zeiss Observer LSM 500 inverted microscope) $10 \times$ magnification.

\section{TRAcP staining}

TRAcP staining was done with TRAP kit 387A-1KT according to the manufacturer's instructions (Sigma-Aldrich Chemie GmbH, Steinheim, Germany).

\section{Quantitative analysis}

For lys $:: D s R E D 2$ transgenic embryos and L-plastin immunostaining, the quantitative analysis was done by counting the total number of cells present in the area around the injection site (ten embryos/group) from flattened $z$ stacks of confocal images. The total number of TRAcP+ cells was counted manually under a compound microscope from the whole body on both sides (ten embryos/group).

\section{Statistical analysis}

Statistical analyses and graphs were performed using GraphPad Prism software version 5.0 (GraphPad Software, Inc, La Jolla, CA). One-way analysis of variance was performed on the data from the mortality, malformations in zebrafish larvae, lysC: DsRED2, and L-plastin 
immunohistochemistry and to analyze the impact of protein-loaded (M-CSFM-CSF and RANK-L) MSNPs on TRAcP-expressing cells. Tukey multiple-comparison post hoc tests were applied to further decompose group comparisons. Student's $t$-tests (two-tailed) were performed to analyze the impact of MSNPs $(10 \mathrm{mg} / \mathrm{mL})$ on cell death analysis. Data are presented as mean \pm standard error of the mean, and a probability level of $5 \%$ was used as the minimal criterion of significance.

\section{Results}

\section{Characterization of MSNPs}

We synthesized MSNPs via a sol-gel technique with a pore-expanding agent (mesitylene) to a CTAB-templated emulsion system. The template was removed with a methanol acidic wash because CTAB has been shown to be toxic for cells ${ }^{41}$ due to its capability to damage biological membranes and cause the release of intracellular enzymes. The effective removal of CTAB was confirmed with FT-IR (Figure 1A and B). Next, the nanoparticle surface was pegylated in order to reduce cluster formations in physiological fluids. The nanomaterials thus synthesized present an inner structure comparable with the MCM-41 (Mobil Crystalline Materials) as previously described, ${ }^{10,42}$ with a honeycomb arrangement of the channels, as shown by the electron micrographs (Figure 1C and D).

The particle size of MSNPs was measured with dynamic light scattering in PBS solution ( $\mathrm{pH}$ 7.2) before and after the pegylation step. The hydrodynamic diameter of the particles, before the surface functionalization, was $985 \mathrm{~nm}$ (polydispersity index $[\mathrm{PDI}] \pm 0.21$ ), indicating an elevated tendency of aggregation. However, after surface modification, the hydrodynamic diameter was $255 \mathrm{~nm}$ (PDI \pm 0.198 ), showing that pegylation results in decreased clustering of the particles. Powder diffraction analysis of the particles revealed a sharp peak at 2.8 theta, showing the presence of a mesoporous structure with a pore diameter of approximately $8 \mathrm{~nm}$.

We used BSA to study the loading and release capacity of MSNPs. BSA was modified with FITC (see Supplementary information) and used to measure the release profiles of MSNPs. Loading capacity of MSNP-BSA in the supernatant was $65 \mathrm{mmol}$ of BSA per gram of MSNPs. The release graph shows the concentration of released BSA in the supernatant, as determined by UV-vis spectroscopy (Figure 1E). It shows a delay of $\sim 1$ hour, due to two factors: (1) the steric hindrance of the BSA, and (2) ionic interaction between the silica scaffold of the nanoparticles and the positive charges of the amino acids of the chain.

\section{Distribution of nanoparticles after injection into embryos}

MSNPs conjugated with FITC were injected into the left flank of zebrafish embryos at $2 \mathrm{dpf}$, caudal to the yolk sac extension (Figure 2A). We found that some nanoparticles were seen circulating in the bloodstream (Figure 2A), whereas others were visible in the tissue at the site of injection and remained there for the duration of the experiment (ie, up to 5 dpf [Figure 2B]; see Supplementary movie 1). The earliest time examined was 10 minutes post injection with confocal laser scanning microscope, at which time the particles were already in the circulation (see Supplementary movie 2).

\section{Toxicity testing}

To see whether nanoparticles had an adverse effect on the development of the embryo we first recorded the cumulative mortality at $5 \mathrm{dpf}$ (Figure 3A). Percentage mortality, pericardial edema, and morphological abnormalities are shown in Figure 3A. Mean mortality in the MSNP-injected group was $5.8 \%$ and $4.1 \%$ in the control group (PBS only; Figure 3A). In the MSNP-injected group, $4.68 \%$ of embryos had pericardial edema and skeletal abnormalities, compared with $1.5 \%$ of controls. The skeletal abnormalities were of Meckel's cartilage, the pharyngeal arches, and the ethmoid plate, as revealed by Alcian blue staining (Figure 3B and C). Cell death, as indicated by acridine orange staining (Figure $3 \mathrm{E}$ ), was quantified for the whole embryo at 24 hours post injection, and was similar in MSNP-injected and control groups (Figure 3D). Statistical analysis showed that there was no significant difference between the MSNP-injected and control (PBS-injected) groups in terms of cell death, mortality, or malformations.

\section{Immune cell response to injection}

We examined the neutrophil response to the injection of MSNPs or PBS (control) in 2 dpf lyz::DsRED2 embryos from 2 hours until 3 days after injection. At 2 hours post injection, the site of injection was already infiltrated by neutrophils (Figure 4A-C; for normal appearance of neutrophil distribution in a healthy untreated zebrafish embryo see Figure S3A). Neutrophils were still in the vicinity of the injection site at 24 hours and 2 days post injection (Figure 4D and E, respectively) and 3 days post injection (Figure 4F). Large aggregations of neutrophils were seen at the site of injection regardless of whether MSNPs or buffer alone was injected (Figure 4A and B). There was no difference between MSNPinjected and PBS-injected embryos in terms of neutrophil infiltration in the larvae 2 days after injection (see Figure S1). Additionally, we performed L-plastin immunostaining to 


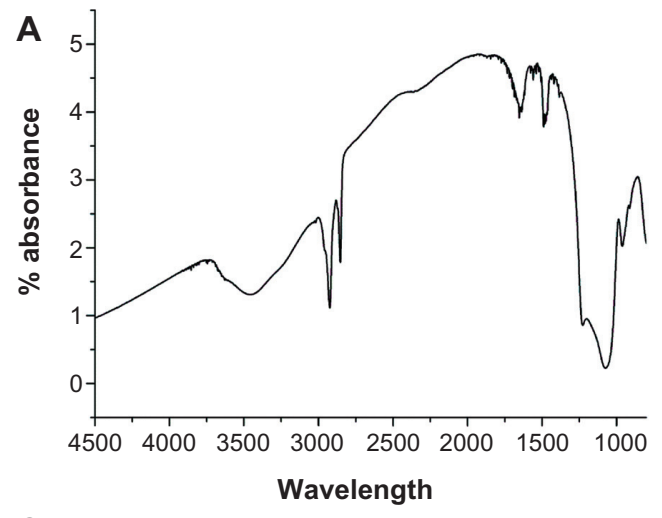

C

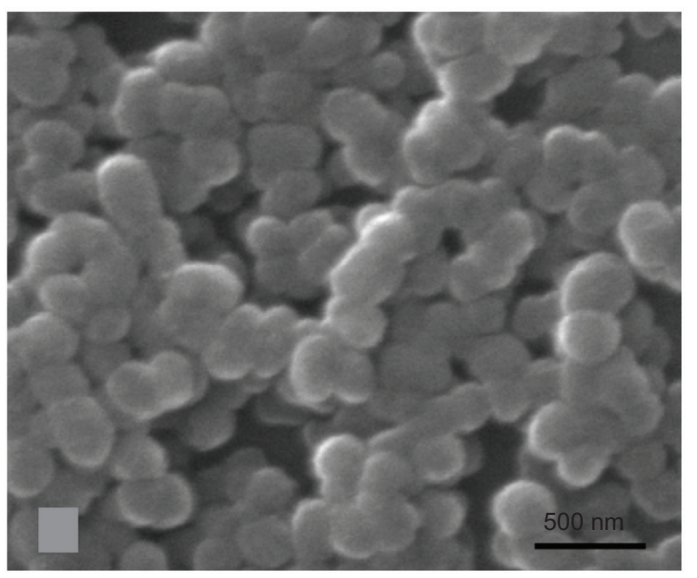

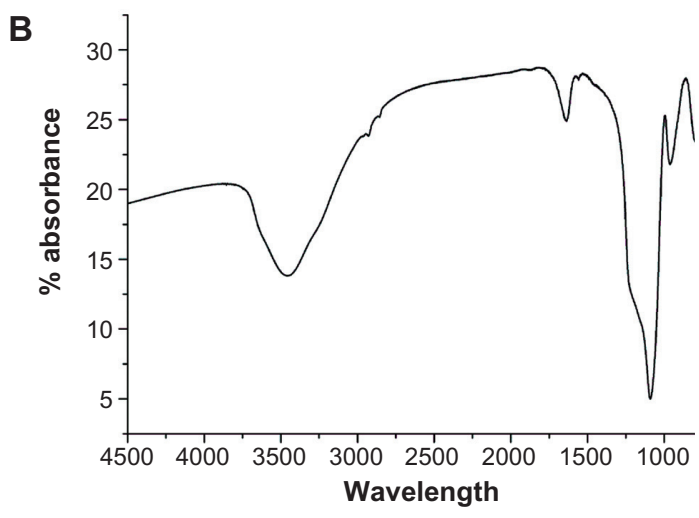

D

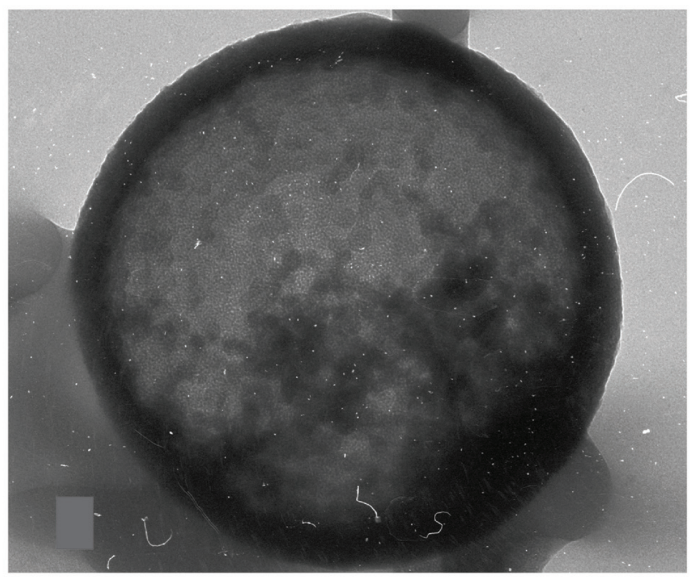

E

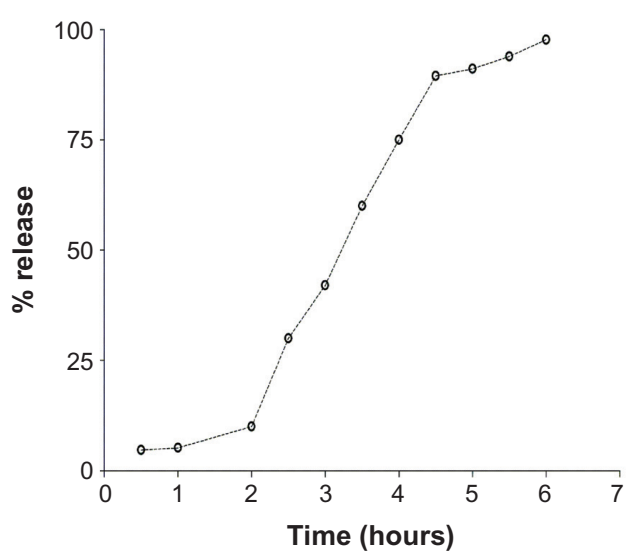

Figure I Characterization of silica nanoparticles. (A) Fourier transform infrared spectroscopy (FT-IR) spectra of mesoporous silica nanoparticles (MSNPs) before removal of hexadecyl trimethyl ammonium bromide (CTAB) template, showing the $\mathrm{C}-\mathrm{H}$ stretch of the alkyl chains of CTAB at $2750 \mathrm{~cm}^{-1}$. (B) FT-IR of MSNPs after the removal of CTAB template with acidic methanol washing. (C) Scanning electron microscopy image of MSNPs showing the homogeneous shape and diameter. (D) Transmission electron microscopy image of MSNP showing homogeneous displacement of parallel channels. (E) Release of fluorescein-5(6) isothiocyanate-bovine serum albumin from MSNPs. A delay of $\sim 1.5$ hours is observed due to the interaction of the bovine serum albumin with the silica scaffold of the nanoparticle.

image and quantify the accumulation of all leukocytes. Like $l y z:: D s R E D 2$ cells, L-plastin-positive cells accumulated around the injection sites in both MSNP-injected and PBSinjected larvae (Figure 4G and H). Quantitative analysis revealed no significant difference between MSNP and control injections (Figure S2).

\section{Compound delivery}

In embryos injected with MSNPs loaded with a combination of $40 \mathrm{ng} / \mathrm{mL}$ of M-CSF and $400 \mathrm{ng} / \mathrm{mL}$ of RANK-L and then suspended in buffer, TRAcP+ cells were observed around the injection site (Figure 5A) and at many other locations distributed all over the body of the larvae (Figure 5A-F; there 

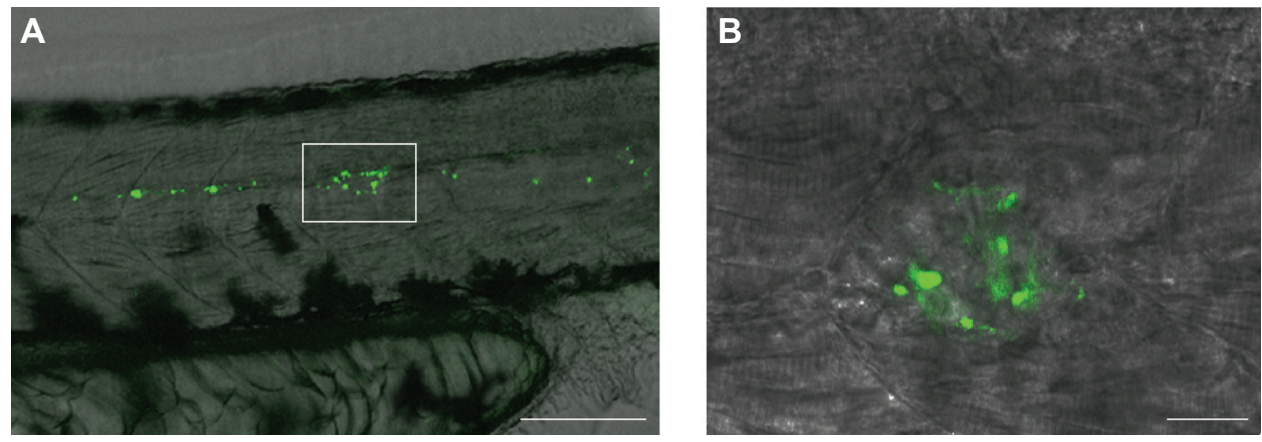

Figure 2 Fluorescent mesoporous silica nanoparticle (MSNP)-injected zebrafish embryos. (A) MSNPs (green) distributed anteriorly and caudally from site of injection (boxed area); the black cells are pigment cells (melanocytes). Scale bar $=100 \mu \mathrm{m}$. (B) MSNPs aggregated at the site of injection. Scale bar $=20 \mu \mathrm{m}$.

A

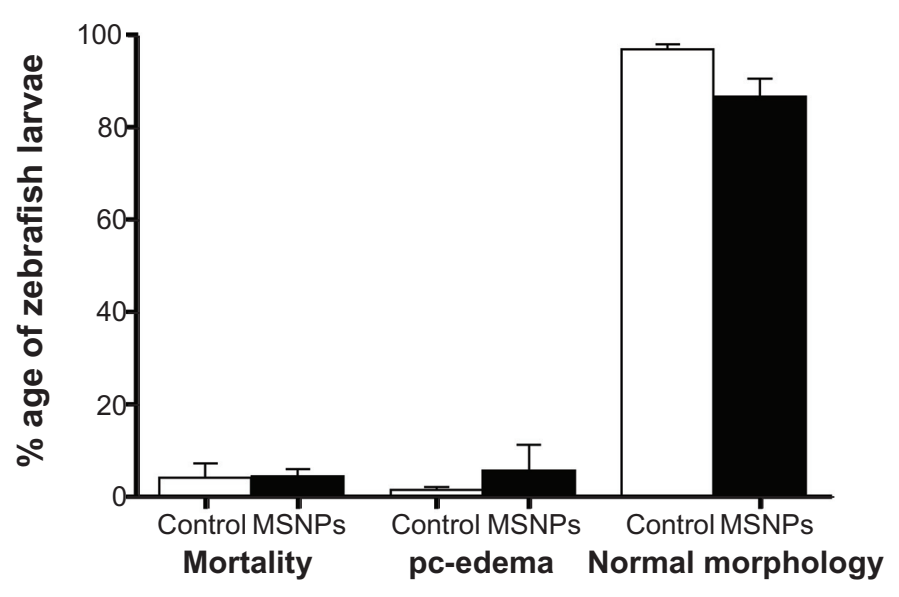

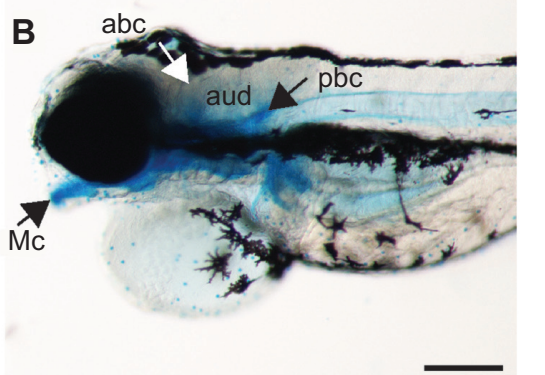

B

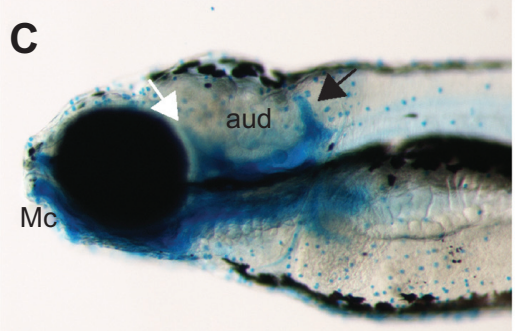

C

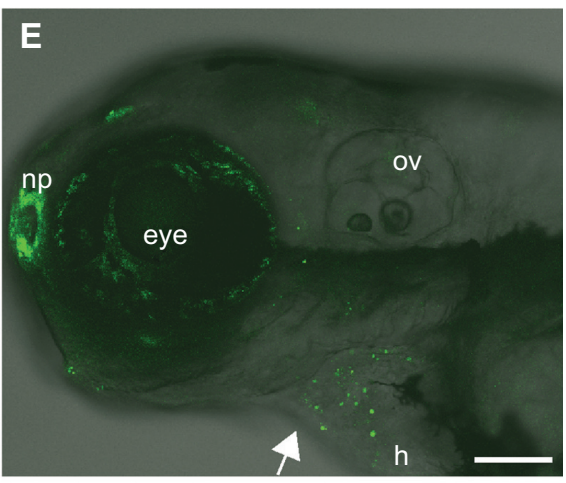

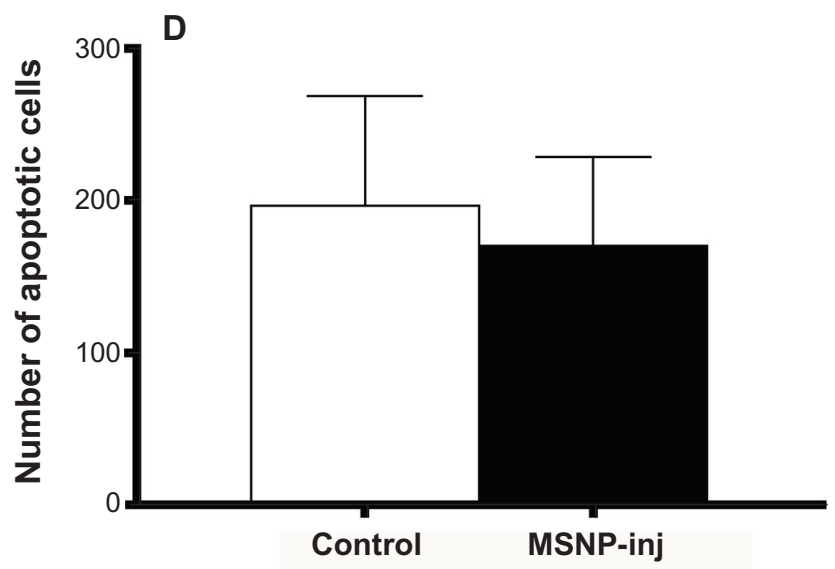

Figure 3 Toxicity of mesoporous silica nanoparticles (MSNPs). (A) Graph showing percentage mortality in zebrafish larvae, larvae affected by pericardial edema, or larvae with normal morphology. The differences between buffer-injected (control) and MSNP-injected (MSNP) embryos are not statistically significant. Bars indicate standard error of mean ( $n=168$ control and $n=96$ for MSNP-injected embryos). The experiment was carried out two times. (B) Embryo injected at 2 days post fertilization (dpf) with MSNPs and fixed and stained at $5 \mathrm{dpf}$ with Alcian blue. It had a combination of abnormalities as follows: pericardial edema, a malformed Meckel's cartilage (Mc), anterior brachial cartilage (abc) (white arrow), posterior branchial cartilage (pbc) (black arrow), and auditory capsule (aud). Scale bar = $200 \mu \mathrm{m}$. (C) Embryo injected at $2 \mathrm{dpf}$ with buffer only, then fixed at $5 \mathrm{dpf}$ and stained with Alcian blue. This embryo shows a normal pharyngeal skeleton. Scale bar $=200 \mu \mathrm{m}$. Although we selected this malformed embryo from the MSNP group and the normal from the controls, there was no significant difference in the incidence of malformed embryos between bufferinjected and MSNP-injected groups ( $\mathrm{n}=25$ per group). (D) Quantification of acridine orange-stained cells in control (buffer-injected) and MSNP groups. There was no significant difference after 24 hours of injection between the two groups (ten embryos per group). (E) Acridine orange-stained embryo with dead cells (green) in the eye, heart (h), and nasal placode (np). Scale bar $=100 \mu \mathrm{m}$.

Notes: Our result shows no difference between the embryos treated with nanoparticles and controls. $P<0.1, P<0.0$ I; $P<0.00 \mathrm{I}$.

Abbreviation: ov, otic vesicle. 
was no expression of TRAcP in control larvae in the head region [Figure $\mathrm{S} 3 \mathrm{C}$ and $\mathrm{D}]$ ). We made a quantitative analysis of the total number of TRAcP+ cells throughout the body of the larvae 1-5 days after the injection of protein-loaded MSNPs. We found a significant increase in the number of TRAcP+ cells from 2 days post injection up to 4 days post injection, compared with the controls. This increase in number seems to be transient, as it returns to normal after 5 days. There was no significant difference in the number of L-plastin+ cells in the cytokine and cytokine-MSNP-injected embryos 2 days and 3 days post injection (Figure S2). There was also the rare presence of apparently multinucleated

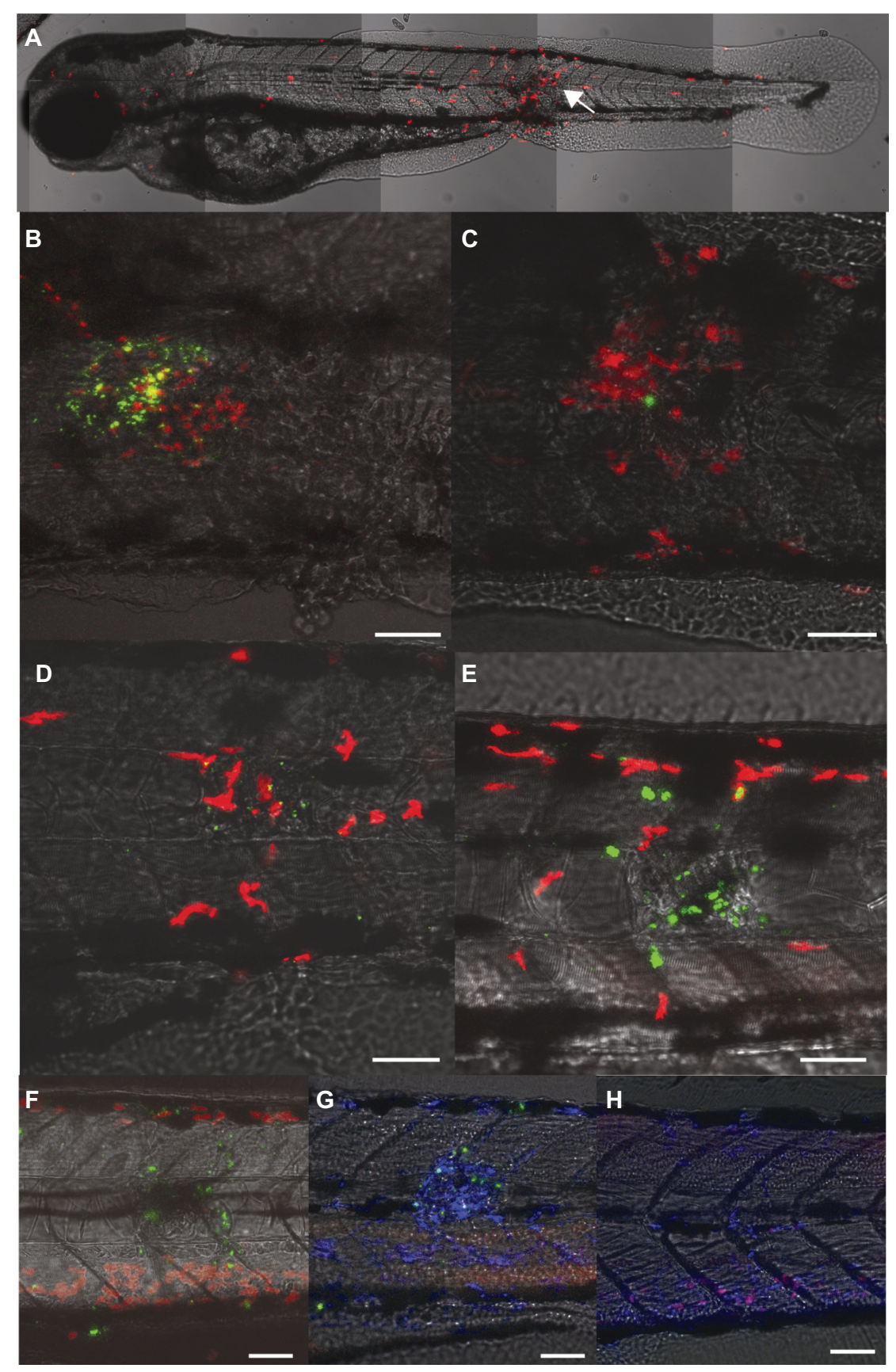

Figure 4 Confocal images showing injection site of lysC::DsRED2 transgenic zebrafish embryos/larvae. (A) Buffer-injected 2 days post fertilization (dpf) embryo 2 hours post injection (overlay of tiles with z stacks). Note the neutrophils (red) at the injection site (arrow) and at more remote sites. (B) An overlay image of a different embryo showing mesoporous silica nanoparticles (MSNPs) (green) and neutrophils (red) at the injection site 2 hours post injection. (C) Representative overlay image of a different embryo injected at $2 \mathrm{dpf}$ with MSNPs and analyzed at 2 hours post injection. This case shows a much smaller accumulation of MSNPs (green) and neutrophils (red) at the injection site than (B). (D) MSNP-injected embryo at 24 hours post injection. MSNPs (green), neutrophils (red). (E) MSNP-injected embryo at 2 dpf. MSNPs (green), neutrophils (red). (F) MSNP-injected embryo at 3 days post injection. MSNPs (green), neutrophils (red). (G) MSNPs (green) in 3 days post injection larva. Leukocytes (blue) detected by L-plastin immunolabeling. (H) Buffer-injected control larva 3 days post injection. Leukocytes (blue) detected by L-plastin immunolabeling. $(\mathbf{B}-\mathbf{H})$ Scale bar $=50 \mu \mathrm{m}$. 

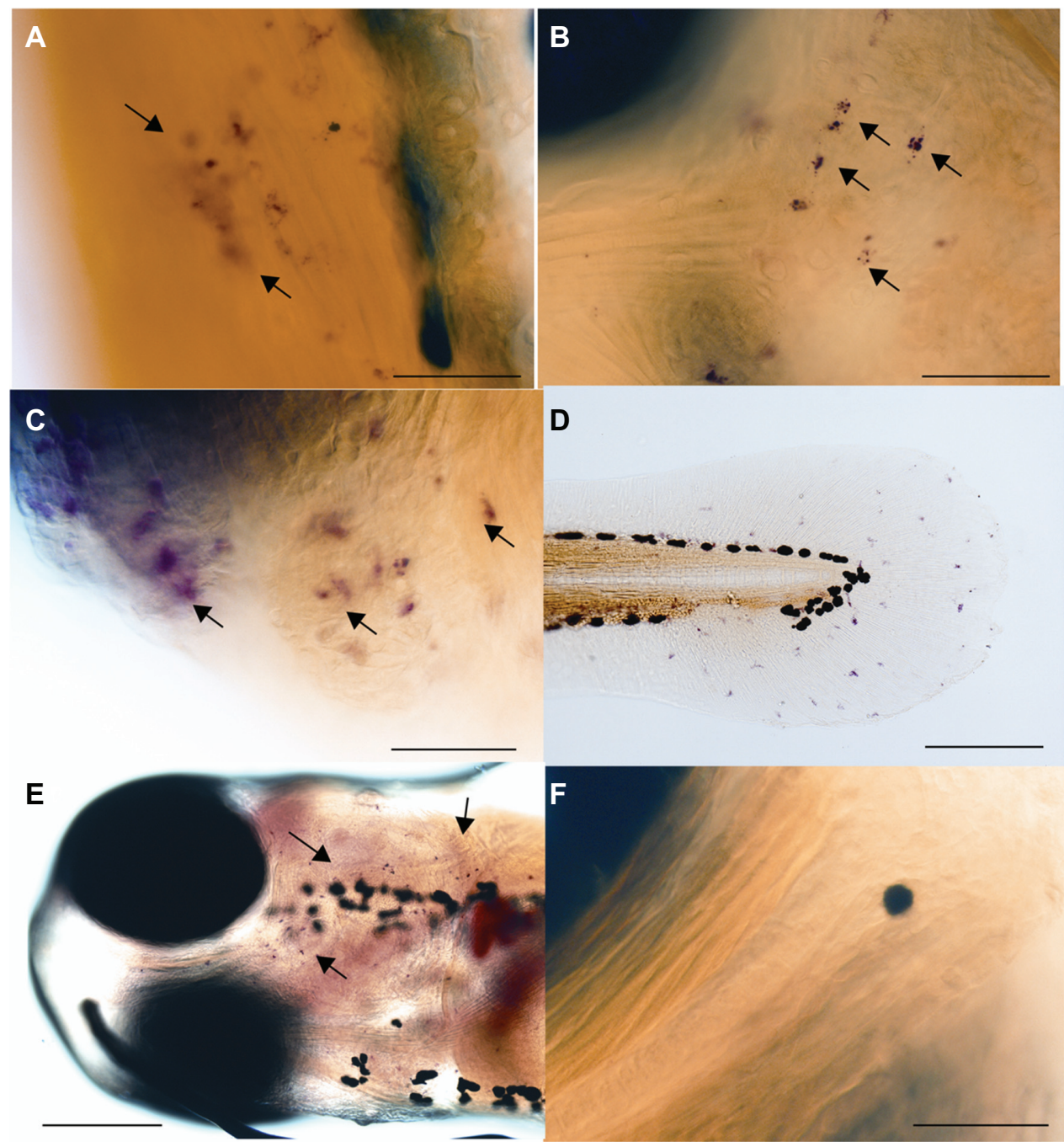

Figure $\mathbf{5}$ Tartrate-resistant acid phosphatase (TRAcP) enzyme staining in mesoporous silica nanoparticle (MSNP)-injected larvae. (A) TRAcP+ cells at the site of injection in the tail of 3 days post injection larva (arrows). (B) TRAcP+ cells in the head region under the eye (arrows) of a 3 days post injection larva. (C) TRAcP+ cells in the heart region of 3 days post injection larva (arrows). (D) TRAcP+ cells in caudal fin of a 4 days post injection larva. (E) TRAcP+ cells in ventral side of head of 4 days post injection larva (arrows). (F) Phosphate-buffered-saline-injected larva 3 days post injection with no TRAcP+cells below the eye. Scale bar $\mathbf{A}, \mathbf{B}, \mathbf{C}, \mathbf{F}=50 \mu \mathrm{m}$; $\mathbf{D}=100 \mu \mathrm{m}$; and $\mathbf{E}=200 \mu \mathrm{m}$.

TRAcP+ cells in cytokine-loaded MSNP-injected embryos (Figure 6A-D). Hematoxylin and TRAcP double-staining showed three to five nuclei in a cell (Figure 6B). One of these apparently multinucleated TRAcP+ cells in the somite area of a 3 days post injection larva in Figure $6 \mathrm{C}$ was counterstained with 4',6-diamidino-2-phenylindole to visualize the nuclei (Figure 6D, boxed area). Quantitative analysis of pegylated cytokine-loaded MSNPs or buffer-loaded MSNPs in 2 days post injection and 3 days post injection groups showed that the number of TRAcP+ cells significantly increased, compared with the buffer-loaded MSNP-injected controls (Figure 6E). It is important to note that effectiveness of MCSF and RANK-L when injected alone was checked for the expression of TRAcP. There was TRAcP expression in large areas of the body of embryo (Figure S3E and F).

\section{Discussion}

We have tested the toxicity and the capacity for controlled drug delivery of MSNPs injected into living zebrafish embryos. We find that there is no significant difference between the toxicity of MSNP injections and buffer-only injections, as measured by several parameters (mortality, cell death, gross malformations). Injection of MSNPs led to an influx of immune cells at the site of injection that persisted for 2-3 days. However, the same type of influx was also seen in embryos injected with buffer alone, suggesting that it is not the MSNPs that are responsible for the immune response but some aspect of the injection procedure itself (eg, tissue damage). Indeed, it has previously been shown that trauma to zebrafish embryos (eg, a fin clip or mechanical wounding with an injection 

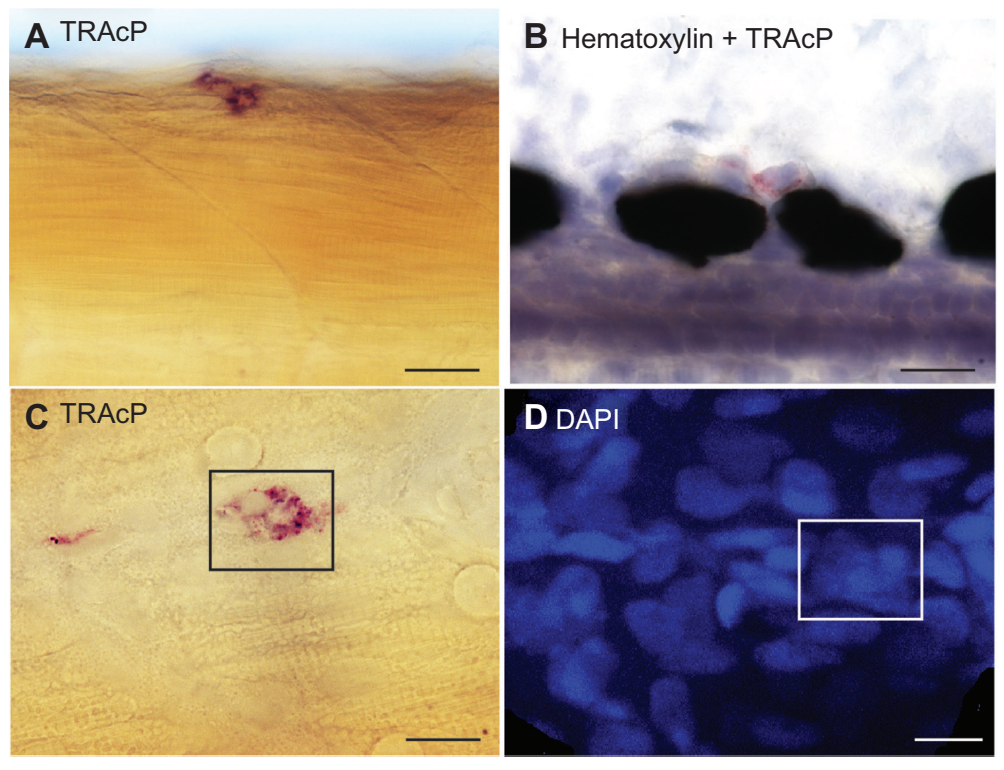

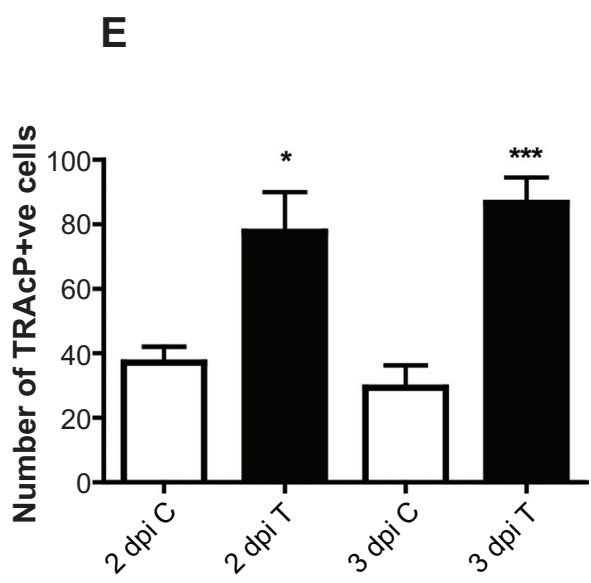

MSNP-injected zebrafish larvae

Figure 6 (A) Tartrate-resistant acid phosphatase (TRAcP) expression in the somites of a 3 days post injection larva with apparently multinuclear cell. (B) TRAcP+ cells counterstained with hematoxylin. (C) TRAcP+ zebrafish larva showing apparently multinuclear cells (box). (D) TRAcP enzyme-stained larva counterstained with 4',6-diamidino-2-phenylindole (DAPI) showing five to six nuclei same area as C (box). Scale bar ABC $=12.5 \mu \mathrm{m}$ and D $=12 \mu \mathrm{m}$. (E) Quantitative analysis of TRAcP+ cells at 2 days post injection (dpi) and $3 \mathrm{dpi}$. Ten larvae/group were used to quantify the number of TRAcP+ cells. Statistical analysis was done with one-way analysis of variance. Notes: $* P<0.1$; *** $P<0.001$. " $C$ " means control (ie, phosphate-buffered-saline injected) and "T" means treated (ie, protein-loaded-MSNP injected).

needle) causes an influx of macrophages and neutrophils to the wound site. ${ }^{23-26}$

In all the studies reported here we used pegylated MSNPs because pegylation is thought to avoid triggering an immune response against the particles. ${ }^{22,43}$ With time-lapse imaging it is clear that some MSNPs remain at the site of injury, whereas others travel in the bloodstream from the site of injection. The MSNPs localized at the site of injection were found to be there even after 3 days. In some embryos, however, the MSNPs stayed in the injection site and did not distribute in the bloodstream.

Due to the high loading capacity of MSNPs we used these particles as a drug carrier for the in vivo delivery of cytokines. This small size helps in fast endocytosis by nonphagocytic cells. ${ }^{44}$ In our studies we found no significant toxic effects of injected MSNPs in the living embryos. This means that at low concentrations, MSNPs could be a very good delivery system in the whole organism. Nanomaterials such as fullerenes have been found to be excreted following oral administration or injections in mice, ${ }^{45}$ whereas others were shown to be taken up by immune cells. We observed very little coexpression of lyz::DsRED2-labeled cells and MSNPs. This may be suggestive of the possibility that few of the particles are phagocytosed by neutrophils. With L-plastin immunolabeling, which stains all leukocytes, more overlap with the fluorescent signal of the particles was observed, suggesting that part of the MSNPs may be phagocytosed by immune cells.
We observed no differences in the number of leukocytes that infiltrated an injection site when nanoparticles were used or when PBS only was injected. We cannot exclude the possibility that nanoparticles had additional effects on immune cells. However, a good positive control for this experiment does not really exist, because any toxic chemical or material injected might induce its own unique effects at the level of gene expression in immune cells, for example. In addition, these possible effects might be very local, and it is technically impossible to exclude that changes in gene expression occur locally in the cells that accumulate at the injection site.

Other studies have shown that in the presence of artificially provided cytokines like M-CSF and RANK-L, immune cells are activated into TRAcP+ osteoclasts. ${ }^{46}$ It is important to note that we found highly increased TRAcP expression in the zebrafish larvae compared with controls after injecting cytokines (M-CSF and RANK-L) alone. We were not able to combine the double-staining of fluorescent immune cells with the histochemical staining of TRAcP enzyme activity, because the two protocols were not compatible. Using single labeling we found a significant increase of TRAcP+ cells in zebrafish larvae injected with MSNP cytokines, whereas there was no significant increase in the total number of immune cells in these embryos. Some of these TRAcP+ cells had multiple nuclei, as shown by 4',6-diamidino-2-phenylindole staining. By 4-5 days post injection, TRAcP+ cells appeared to become small and darkly stained. One possible explanation 
for these observations is that the TRAcP+ cells were transiently induced by the injected cytokines in the early period (2-4 days) after injection, and returned to a normal level later on. It is important to note here that the cytokines have been found in our pilot studies to have effectively activated the TRAcP expression in the embryos.

Further work is required to clarify the differentiation status of the TRAcP+ cells. If it can be confirmed that young larvae have inducible osteoclast-like cells, this would be interesting because zebrafish larvae have not previously been reported to have osteoclasts at the stages studied here. Furthermore, the presence of osteoclast-like cells in zebrafish larvae could lead to a disease model for bone disorders and for the study of effects, for example, of antiosteoporotic drugs. What is clear from our findings is that MSNPs can be used for drug or compound delivery in the zebrafish embryo, with no excess of gross toxic effects or immune responses attributable to the nanoparticles themselves.

\section{Acknowledgments}

We would like to thank GEM Lamers for her great help and cooperation with confocal imaging; PJ Steenbergen, U Nehrdich, and DNJ de Witt for fish care and maintenance; and MAG de Bakker for expert technical assistance. The lyz::DsRED2 line was kindly provided by Dr P Crosier (University of Auckland, Auckland, New Zealand), and the L-plastin antibody was a gift from Dr A Huttenlocher (University of Wisconsin, Madison, WI). The authors gratefully acknowledge the support of the SmartMix Program of the Netherlands Ministry of Economic Affairs and the Netherlands Ministry of Education, Culture, and Science.

\section{Disclosure}

The authors report no conflicts of interest in this work.

\section{References}

1. Singh S, Nalwa HS. Nanotechnology and health safety - toxicity and risk assessments of nanostructured materials on human health. J Nanosci Nanotechnol. 2007;7:3048-3070.

2. Medintz IL, Uyeda HT, Goldman ER, Mattoussi H. Quantum dot bioconjugates for imaging, labelling and sensing. Nat Mater. 2005;4: 435-446.

3. Caruthers SD, Wickline SA, Lanza GM. Nanotechnological applications in medicine. Curr Opin Biotechnol. 2007;18:26-30.

4. Dobrovolskaia MA, McNeil SE. Immunological properties of engineered nanomaterials. Nat Nanotechnol. 2007;2:469-478.

5. Duncan R, Izzo L. Dendrimer biocompatibility and toxicity. Adv Drug Deliv Rev. 2005;57:2215-2237.

6. Oberdorster G, Oberdorster E, Oberdorster J. Nanotoxicology: an emerging discipline evolving from studies of ultrafine particles. Environ Health Perspect. 2005;113:823-839.

7. Smart SK, Cassady AI, Lu GQ, Martin DJ. The biocompatibility of carbon nanotubes. Carbon. 2006;44:1034-1047.
8. Hardonk MJ, Harms G, Koudstaal J. Zonal heterogeneity of rat hepatocytes in the in vivo uptake of $17 \mathrm{~nm}$ colloidal gold granules. Histochemistry. 1985;83:473-477.

9. Nakamura E, Isobe H. Functionalized fullerenes in water. The first 10 years of their chemistry, biology, and nanoscience. Acc Chem Res. 2003;36:807-815.

10. Slowing I, Trewyn BG, Lin VS. Effect of surface functionalization of MCM-41-type mesoporous silica nanoparticles on the endocytosis by human cancer cells. J Am Chem Soc. 2006;128: 14792-14793.

11. Slowing II, Trewyn BG, Lin VSY. Mesoporous silica nanoparticles for intracellular delivery of membrane-impermeable proteins. J Am Chem Soc. 2007; 129:8845-8849.

12. Lu J, Liong M, Zink J, Tamanoi F. Mesoporous silica nanoparticles as a delivery system for hydrophobic anticancer drugs. Small. 2007;3:1341-1346.

13. Lai CY, Trewyn BG, Jeftinija DM, et al. A mesoporous silica nanosphere-based carrier system with chemically removable $\mathrm{CdS}$ nanoparticle caps for stimuli-responsive controlled release of neurotransmitters and drug molecules. J Am Chem Soc. 2003;125: 4451-4459.

14. Rejman J, Oberle V, Zuhorn IS, Hoekstra D. Sizedependent internalization of particles via the pathways of clathrin- and caveolae-mediated endocytosis. Biochem J. 2004;377: $159-169$.

15. Griffitt RJ, Luo J, Gao J, Bonzongo JC, Barber DS. Effects of particle composition and species on toxicity of metallic nanomaterials in aquatic organisms. Environ Toxicol Chem. 2008;27:1972-1978.

16. Klaine SJ, Alvarez PJ, Batley GE, et al. Nanomaterials in the environment: behavior, fate, bioavailability, and effects. Environ Toxicol Chem. 2008;27:1825-1851.

17. Oberdorster E. Manufactured nanomaterials (fullerenes, C60) induce oxidative stress in the brain of juvenile largemouth bass. Environ Health Perspect. 2004;112:1058-1062.

18. Kashiwada S. Distribution of nanoparticles in the see-through medaka Oryzias latipes. Environ Health Perspect. 2006;114:1697-1702.

19. Brunner TJ, Wick P, Manser P, et al. In vitro cytotoxicity of oxide nanoparticles: comparison to asbestos, silica, and the effect of particle solubility. Environ Sci Technol. 2006;40:4374-4381.

20. Fent K, Weisbrod CJ, Wirth-Heller A, Pieles U. Assessment of uptake and toxicity of fluorescent silica nanoparticles in zebrafish (Danio rerio) early life stages. Aquat Toxicol. 2010;100:218-228.

21. Akerman ME, Chan WC, Laakkonen P, Bhatia SN, Ruoslahti E. Nanocrystal targeting in vivo. Proc Natl Acad Sci U S A. 2002;99: 12617-12621.

22. Paciotti GF, Myer L, Weinreich D, et al. Colloidal gold: a novel nanoparticle vector for tumor directed drug delivery. Drug Deliv. 2004;11:169-183.

23. Mathias JR, Dodd ME, Walters KB, Yoo SK, Ranheim EA, Huttenlocher A. Characterization of zebrafish larval inflammatory macrophages. Dev Comp Immunol. 2009;33:1212-1217.

24. Mathias JR, Perrin BJ, Liu TX, Kanki J, Look AT, Huttenlocher A. Resolution of inflammation by retrograde chemotaxis of neutrophils in transgenic zebrafish. J Leukoc Biol. 2006;80:1281-1288.

25. Hall C, Flores MV, Storm T, Crosier K, Crosier P. The zebrafish lysozyme $\mathrm{C}$ promoter drives myeloid-specific expression in transgenic fish. BMC Dev Biol. 2007;7:42.

26. Meijer AH, van der Sar AM, Cunha C, et al. Identification and realtime imaging of a myc-expressing neutrophil population involved in inflammation and mycobacterial granuloma formation in zebrafish. Dev Comp Immunol. 2008;32:36-49.

27. Dahm R, Geisler R. Learning from small fry: the zebrafish as a genetic model organism for aquaculture fish species. Mar Biotechnol NY. 2006;8:329-345

28. Kimmel CB, Ballard WW, Kimmel SR, Ullmann B, Schilling TF. Stages of embryonic development of the zebrafish. Dev Dyn. 1995;203:253-310. 
29. de VE, Sharif F, Metz JR, Flik G, Richardson MK. Matrix metalloproteinases in osteoclasts of ontogenetic and regenerating zebrafish scales. Bone. 2011;48:704-712.

30. Spoorendonk KM, Hammond CL, Huitema LFA, Vanoevelen J, Schulte-Merker S. Zebrafish as a unique model system in bone research: the power of genetics and in vivo imaging. J Appl Ichthyol. 2010;26:219-224.

31. Flores MV, Lam EY, Crosier P, Crosier K. A hierarchy of Runx transcription factors modulate the onset of chondrogenesis in craniofacial endochondral bones in zebrafish. Dev Dyn. 2006;235: 3166-3176.

32. Yan YL, Willoughby J, Liu D, et al. A pair of Sox: distinct and overlapping functions of zebrafish sox 9 co-orthologs in craniofacial and pectoral fin development. Development. 2005;132:1069-1083.

33. Li N, Felber K, Elks P, Croucher P, Roehl HH. Tracking gene expression during zebrafish osteoblast differentiation. Dev Dyn. 2009;238:459-466.

34. Udagawa N, Takahashi N, Akatsu T, et al. Origin of osteoclasts: mature monocytes and macrophages are capable of differentiating into osteoclasts under a suitable microenvironment prepared by bone marrowderived stromal cells. Proc Natl Acad Sci U S A. 1990;87:7260-7264.

35. Collin-Osdoby P, Yu X, Zheng H, Osdoby P. RANKL-mediated osteoclast formation from murine RAW 264.7 cells. Methods Mol Med. 2003;80:153-166.

36. Ogris M, Brunner S, Schuller S, Kircheis R, Wagner E. PEGylated DNA/ transferrin-PEI complexes: reduced interaction with blood components, extended circulation in blood and potential for systemic gene delivery. Gene Ther. 1999;6:595-605.

37. Gref R, Luck M, Quellec P, et al. 'Stealth' corona-core nanoparticles surface modified by polyethylene glycol PEG.): influences of the corona PEG chain length and surface density and of the core composition on phagocytic uptake and plasma protein adsorption. Colloids Surf B Biointerfaces. 2000;18:301-313.
38. Ellett F, Pase L, Hayman JW, Andrianopoulos A, Lieschke GJ. mpeg1 promoter transgenes direct macrophage-lineage expression in zebrafish. Blood. 2011;117:e49-e56.

39. Cui C, Benard EL, Kanwal Z, et al. Infectious disease modeling and innate immune function in zebrafish embryos. Methods Cell Biol. In press.

40. Mathias JR, Perrin BJ, Liu TX, Kanki J, Look AT, Huttenlocher A. Resolution of inflammation by retrograde chemotaxis of neutrophils in transgenic zebrafish. J Leukoc Biol. 2006;80(6):1281-1288.

41. Wang S, Lu W, Tovmachenko O, Rai US, Yu H, Ray PC. Challenge in understanding size and shape dependent toxicity of gold nanomaterials in human skin keratinocytes. Chemical Physics Letters. 2008;463:145-149.

42. Wark M, Ortlam A, Ganschow M, Schulz-Ekloff G, Wöhrle D. Monomeric encapsulation of phthalocyanine-dye molecules in the pores of Si-MCM-41 and Ti-MCM-41. Berichte der Bunsengesellschaft für physikalische Chemie. 1998;102:1548-1553.

43. Fischer HC, Chan WC. Nanotoxicity: the growing need for in vivo study. Curr Opin Biotechnol. 2007;18:565-571.

44. Saba TM. Physiology and physiopathology of the reticuloendothelial system. Arch Intern Med. 1970;126:1031-1052.

45. Yamago $\mathrm{S}$, Tokuyama $\mathrm{H}$, Nakamura $\mathrm{E}$, et al. In vivo biological behavior of a water-miscible fullerene: 14C labeling, absorption, distribution, excretion and acute toxicity. Chem Biol. 1995;2:385-389.

46. Lorenzo J. Characterization of osteoclast precursor cells in murine bone marrow. J Musculoskelet Neuronal Interact. 2003;3:273-277. 


\section{Supplementary information}

Silica nanoparticles as a compound delivery system in zebrafish embryos

Fluorescent labeling of bovine serum albumin and loading of mesoporous silica nanoparticles

To detect the release of protein from silica nanoparticles, bovine serum albumin (BSA), a protein of $66 \mathrm{kDa}$, was used instead of receptor for necrosis factor ligand (RANK-L) and macrophage colony-stimulating factor (M-CSF) human recombinant proteins. This is because it is commercially available in much larger quantities and at much lower cost than the cytokines used in this study. BSA $(50.2 \mathrm{mg}, 0.7 \mu \mathrm{mol})$ was dissolved in $20 \mathrm{~mL}$ of $0.1 \mathrm{M}$ sodium bicarbonate solution, $\mathrm{pH}$ 9.0. A solution $0.1 \mathrm{mM}$ of fluorescein-5(6) isothiocyanate (FITC) isomer 1 was prepared in dimethyl sulfoxide, and $5 \mathrm{~mL}$ of this solution was added in drops to the protein solution and stirred at room temperature for 2 hours, followed by 12 hours at $4^{\circ} \mathrm{C}$. After this, $42 \mathrm{mg}$ of ammonium chloride was added to the solution, and the mixture was stirred for another 2 hours at room temperature. The resulting FITC-labeled protein was then purified via dialysis using a dialysis membrane with a cut-off of 10,000 MW. After freeze drying, the labeled protein was recovered as an orange solid, yielding $82 \%$ (41.164 mg, $0.574 \mu \mathrm{mol}$ ) of final product. The isolated FITC-BSA was then characterized via ultraviolet-visible (UV-vis) absorption spectroscopy, and the labeling efficiency was determined to be 1.5 moles FITC per 1 mole of protein. The UV-vis absorbance spectra were measured with a UV-vis spectrophotometer (Perkin-Elmer Ltd, Beaconsfield, UK).

\section{Analysis of zebrafish embryos \\ Mortality}

The number of dead embryos was recorded every 24 hours for up to 3 days after injection.

\section{Morphology}

The live larvae were analyzed for malformations, namely edema of the pericardium and/or yolk sac, microphthalmia, and abnormal body curvature, every 24 hours. Furthermore, gross abnormalities of the chondral skeleton were assessed in 5-dayold zebrafish embryos fixed and Alcian blue-stained larvae.

\section{Cell death}

For necrosis assay the larvae from both the treatment and control groups 24 hours post injection were live stained with $5 \mathrm{mg} / \mathrm{L}$ acridine orange solution in egg water for 30 minutes in the dark. They were then assessed with confocal microscopy at an excitation wavelength of $488 \mathrm{~nm}$ to count the number of positive cells in the entire body of the living larva. The necrotic cells were counted from the confocal images after $z$ stack was flattened to get a clear picture of all the cells through the thickness of the embryo.

\section{Alcian blue staining}

The larvae were fixed at 5 days post fertilization (dpf) in $4 \%$ paraformaldehyde in PBS at $4{ }^{\circ} \mathrm{C}$ overnight, then rinsed in Milli-Q water $5 \times 5$ minutes and dehydrated in a graded series of ethanols $(25 \%, 50 \%, 70 \%)$, rinsed in acid alcohol ( $1 \%$ concentrated hydrochloric acid in 70\% ethanol) for 10 minutes, and placed in filtered Alcian blue solution $(0.03 \%$ Alcian blue) in acid alcohol for 1 hour. They were then washed $2 \times 30$ minutes in distilled water, cleared in $70 \%$ glycerol, and stored until imaging. Twenty-five embryos each from the treatment and control groups were observed.

Morphometric analyses of cell death, neutrophil, leukocyte/macrophage, and tartrate-resistant acid phosphatase-positive cells

Acridine orange-stained cells were counted from confocal images of whole zebrafish embryos under anesthesia (MS222). Ten embryos each were used for morphometric analyses per group (ie, treatment and control). Similarly, tartrate-resistant acid phosphatase-positive cells were counted manually under a compound microscope. The cell count was done for seven embryos per group for both types of

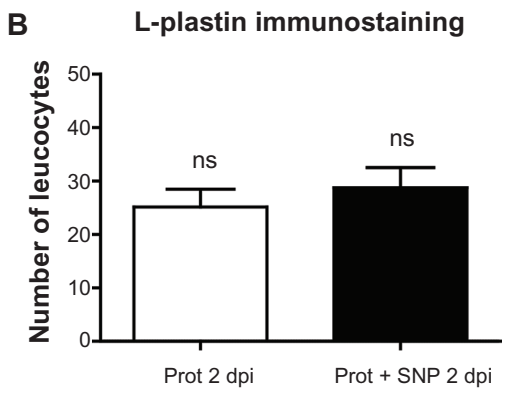

Figure SI Morphometric analysis of immune cells in lysC::DsRED2 transgenic embryos. (A) Number of neutrophils 2 days post-injection (dpi) of phosphate-buffered saline (PBS) (veh) and mesoporous silica nanoparticles (MSNPs). (B) L-plastin+ leukocytes 2 dpi of PBS (veh) and MSNPs. 
A

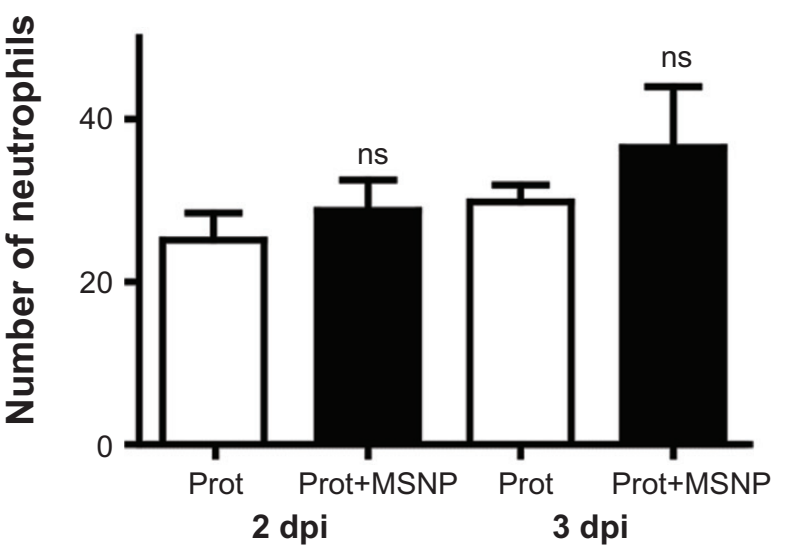

C Lys ds red transgenic

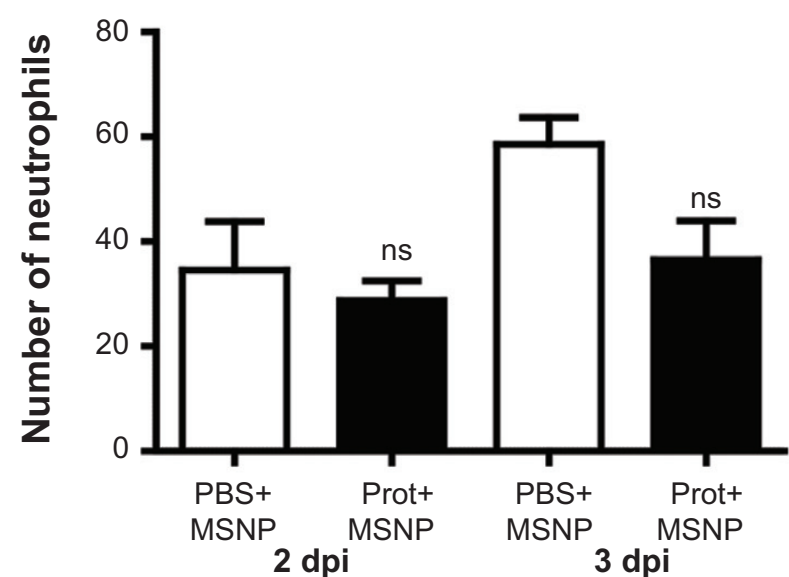

E L-plastin immunostaining

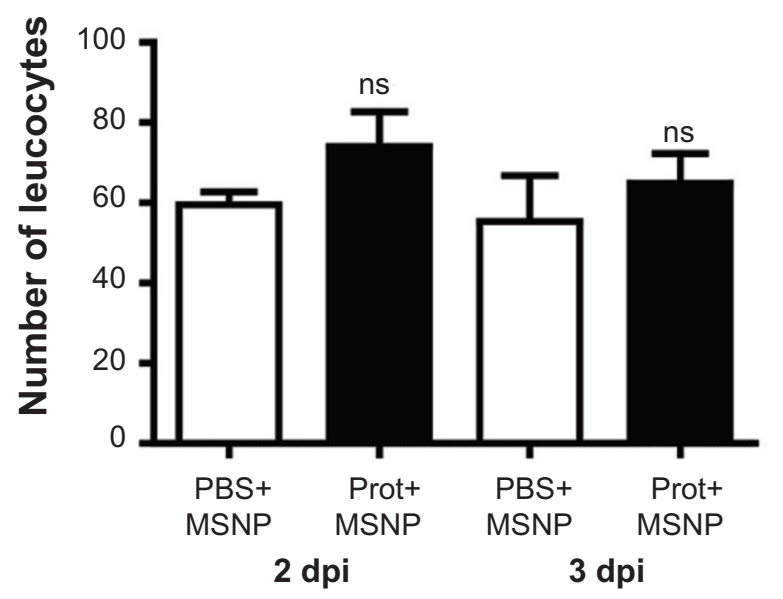

B

Lys ds red transgenic

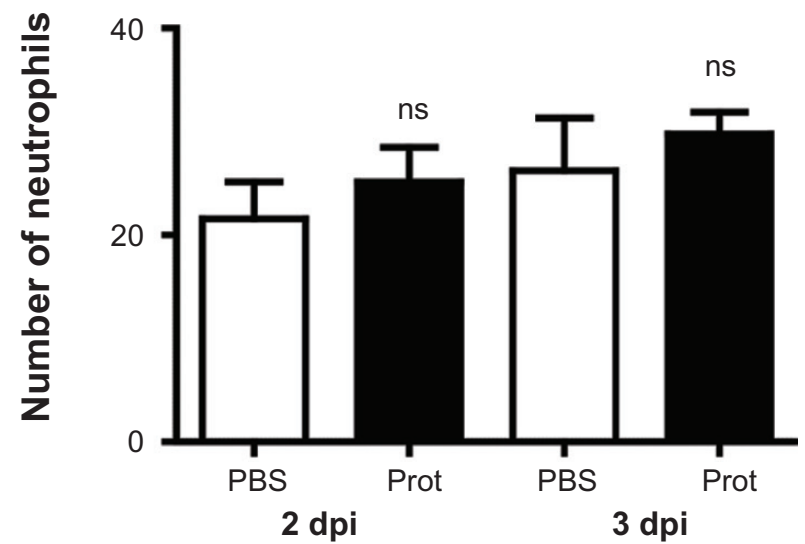

D L-plastin immunostaining

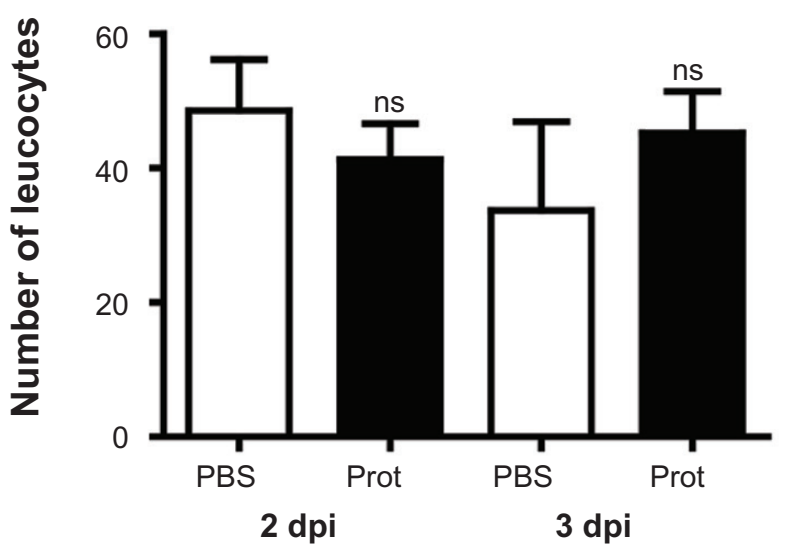

F L-plastin immunostaining

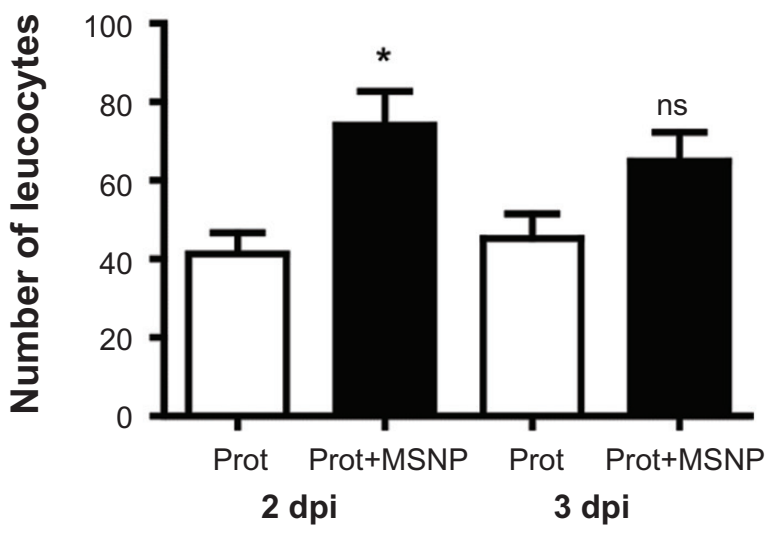

Figure S2 (A) Number of neutrophils 2 and 3 days post injection (dpi) with proteins (prot) or mesoporous silica nanoparticles (prot+MSNP). (B) Number of neutrophils 2 dpi and $3 \mathrm{dpi}$ of phosphate-buffered saline (PBS) and protein. (C) Number of neutrophils $2 \mathrm{dpi}$ and $3 \mathrm{dpi}$ of MSNPs with or without proteins. (D) Number of leukocytes $2 \mathrm{dpi}$ or $3 \mathrm{dpi}$ of MSNP+PBS or proteins+MSNP. (E) Number of leukocytes 2 dpi or 3 dpi of protein or protein+MSNP. (F) Number of total leukocytes 2 dpi or 3 dpi of PBS or protein. Note that the protein means the macrophage colony-stimulating factor and receptor for necrosis factor ligand loaded into the nanoparticles, which in turn are suspended in PBS. Note: $* P<0$.I.

Abbreviation: ns, not significant. 


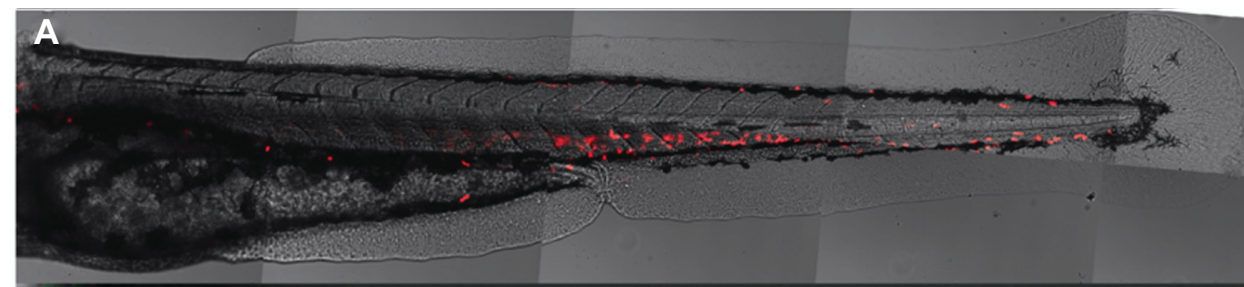

B

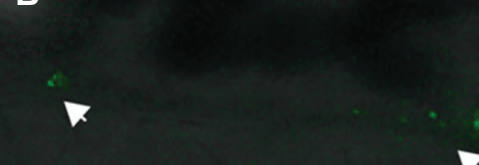

R
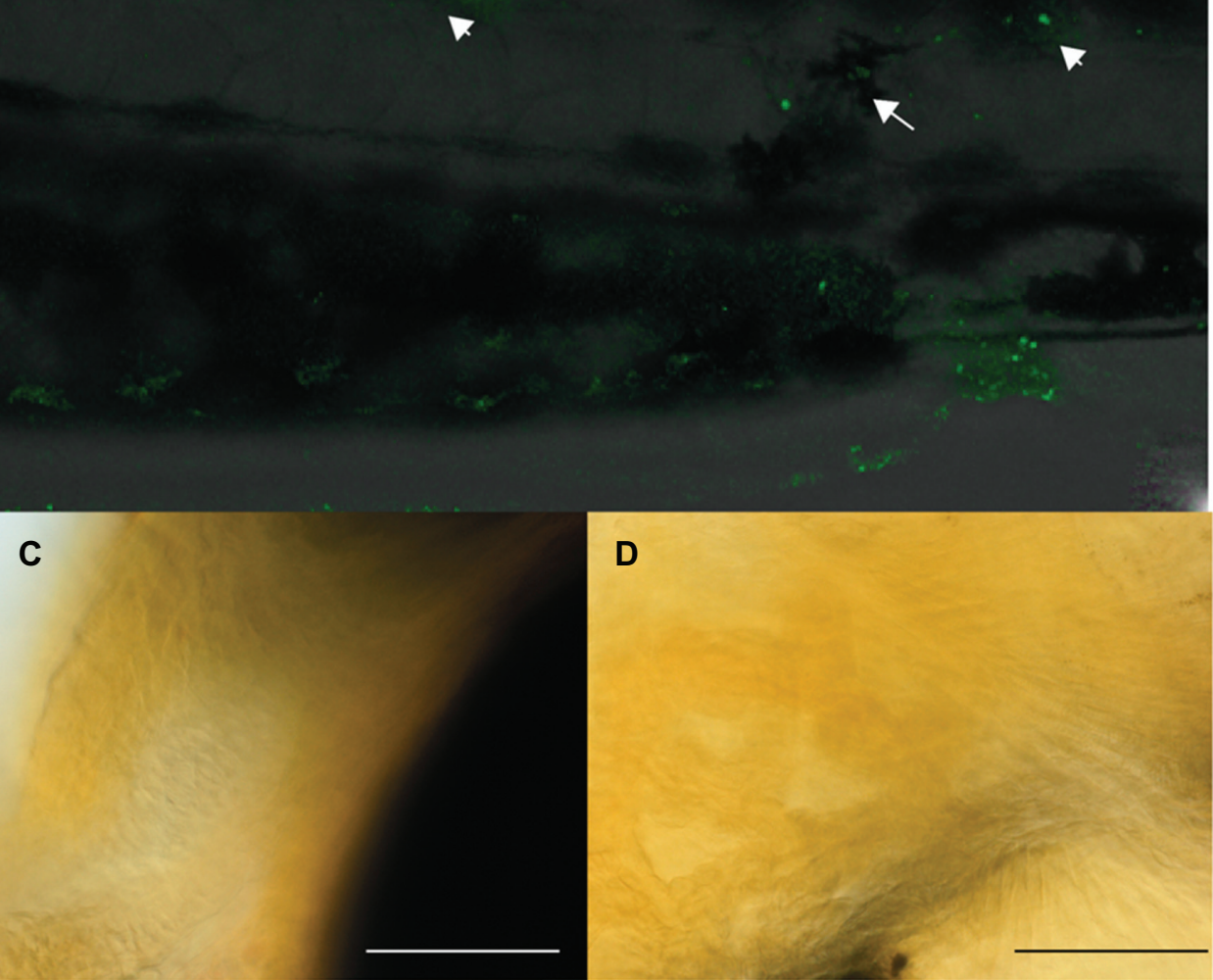

D

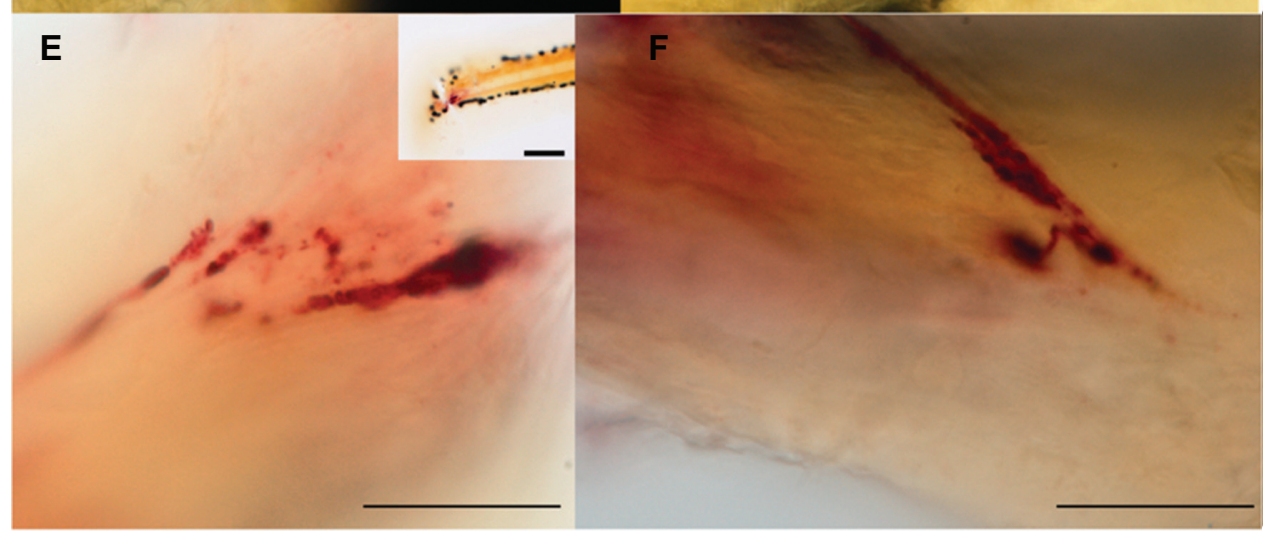

Figure S3 (A) Additional figures showing a control larva without any injection after 24 hours of injection. Neutrophils (red) are normally distributed in the hematopoietic tissue. No cells are found in the tissue of the somites. (B) Embryo showing cell death by acridine orange staining in the posterior region of the body injected with mesoporous silica nanoparticles (MSNPs) after 24 hours of injection. Note here that the arrow shows the MSNPs in the area of injection and arrowheads point toward lateral line organs. (C) Head region of a control larva after tartrate-resistant acid phosphatase (TRAcP) enzyme staining with no TRAcP stained cells. (D) Another view of head region of a control larva after TRAcP enzyme staining with no stained cells. (E) 5 dpf zebrafish larva after cytokine only injection (I0 $\mu \mathrm{g} / \mathrm{mL} \mathrm{M}-\mathrm{CSF}$ and I00 $\mu \mathrm{g} / \mathrm{mL}$ RANK-L) without using MSNPs. Tartrate-resistant acid phosphatase enzyme staining reveals a highly increased TRAcP expression in the tail region (scale bar $=20 \mu \mathrm{m}$ ); inset shows the posterior region of the same larva at a low magnification $($ scale bar $=100 \mu \mathrm{m})$. (F) Another image of the same embryo $($ scale bar $=20 \mu \mathrm{m})$. 
cells (lysozyme-positive neutrophils and L-plastin-positive leukocytes). For acridine orange and tartrate-resistant acid phosphatase, cells in the entire body of the embryo were counted. For immune cells, only the area around the injection site was counted.

Supplementary movie I Two-days post-fertilization zebrafish embryo injected with fluorescent nanoparticles (green) in the left flank behind yolk sac extension showing the movement and distribution of mesoporous silica nanoparticles for the first 2.5 hours after injection. There was an interval of 10 minutes between each frame. Available from: http://youtu.be/mPsLIGAApUg.
Supplementary movie 2 A different, 2-days post-fertilization zebrafish embryo, injected with fluorescent nanoparticles (green) in the left flank behind yolk sac extension showing the movement and distribution of mesoporous silica nanoparticles later than 2.5 hours. The recording was done from 2.5 hours post injection to 5 hours post injection. There was an interval of 10 minutes between each frame. Available from: http://youtu.be/_6sY-II0_Oc.

\section{Reference}

1. Lyubchenko YL, Gall AA, Shlyakhtenko LS, et al. Atomic force microscopy imaging of double stranded DNA and RNA. J Biomol Struct Dyn. 1992;10:589-606.

\section{Publish your work in this journal}

The International Journal of Nanomedicine is an international, peerreviewed journal focusing on the application of nanotechnology in diagnostics, therapeutics, and drug delivery systems throughout the biomedical field. This journal is indexed on PubMed Central, MedLine, CAS, SciSearch ${ }^{\circledR}$, Current Contents ${ }^{\circledR} /$ Clinical Medicine,
Journal Citation Reports/Science Edition, EMBase, Scopus and the Elsevier Bibliographic databases. The manuscript management system is completely online and includes a very quick and fair peer-review system, which is all easy to use. Visit http://www.dovepress.com/ testimonials.php to read real quotes from published authors. 